\title{
Left ventricular dysfunction with reduced functional cardiac reserve in diabetic and non-diabetic LDL-receptor deficient apolipoprotein B100-only mice
}

Suvi E Heinonen', Mari Merentie', Marja Hedman², Petri I Mäkinen', Elina Loponen', Ivana Kholová1,3, Fatima Bosch ${ }^{4}$, Markku Laakso ${ }^{5}$ and Seppo Ylä-Herttuala ${ }^{1 *}$

\begin{abstract}
Background: Lack of suitable mouse models has hindered the studying of diabetic macrovascular complications. We examined the effects of type 2 diabetes on coronary artery disease and cardiac function in hypercholesterolemic low-density lipoprotein receptor-deficient apolipoprotein B100-only mice (LDLR $\left.{ }^{-/} A p o B^{100 / 100}\right)$. Methods and results: 18-month-old $\operatorname{LDLR}^{-/} \operatorname{ApoB}^{100 / 100}(n=12)$, diabetic $\operatorname{LDLR}^{-/} A p o B^{100 / 100}$ mice overexpressing insulin-like growth factor-II (IGF-II) in pancreatic beta cells (IGF-II/LDLR $\left.{ }^{-1} A p o B^{100 / 100}, n=14\right)$ and age-matched C57BI/6 mice $(n=15)$ were studied after three months of high-fat Western diet. Compared to $L^{2} L^{-1 /} A p o B^{100 / 100}$ mice, diabetic IGF-II/LDLR ${ }^{-1-}$ ApoB ${ }^{100 / 100}$ mice demonstrated more calcified atherosclerotic lesions in aorta. However, compensatory vascular enlargement was similar in both diabetic and non-diabetic mice with equal atherosclerosis (cross-sectional lesion area $\sim 60 \%$ ) and consequently the lumen area was preserved. In coronary arteries, both hypercholesterolemic models showed significant stenosis ( 80\%) despite positive remodeling. Echocardiography revealed severe left ventricular systolic dysfunction and anteroapical akinesia in both $\mathrm{LDLR}^{-/-}$ApoB ${ }^{100 / 100}$ and IGF-II/ $\mathrm{LDLR}^{-/} A \mathrm{ApoB}^{100 / 100}$ mice. Myocardial scarring was not detected, cardiac reserve after dobutamine challenge was preserved and ultrasructural changes revealed ischemic yet viable myocardium, which together with coronary artery stenosis and slightly impaired myocardial perfusion suggest myocardial hibernation resulting from chronic hypoperfusion.
\end{abstract}

Conclusions: $\mathrm{LDLR}^{-/-} A p \mathrm{~B}^{100 / 100}$ mice develop significant coronary atherosclerosis, severe left ventricular dysfunction with preserved but diminished cardiac reserve and signs of chronic myocardial hibernation. However, the cardiac outcome is not worsened by type 2 diabetes, despite more advanced aortic atherosclerosis in diabetic animals.

\section{Background}

Type 2 diabetes is associated with a marked increase in the risk of coronary heart disease [1,2]. Still, the mechanisms underlying macrovascular diseases in type 2 diabetic patients remain unclear. In recent years various models combining disorders of lipid and glucose metabolism have been generated and they have provided

\footnotetext{
* Correspondence: seppo.ylaherttuala@uef.fi

'Department of Biotechnology and Molecular Medicine at A.I. Virtanen Institute for Molecular Sciences, University of Eastern Finland, P.O. Box 1627, Fl-70211 Kuopio, Finland

Full list of author information is available at the end of the article
}

valuable information. However, better and more appropriate models are urgently needed.

To date, development of mouse models describing diabetic macrovascular disease has been limited. The effect of hyperglycemia has been widely studied in atherosclerotic models by streptozotosin-induced beta cell destruction [3]. However, while hyperglycemia is an important factor in microvascular complications of diabetes, its role in macrovascular events is less dominant [4] and animal studies have not been consistent [5-8]. Thus, achieving models representing the overall metabolic changes typical for diabetic patients with the 
highest risk of macrovascular complications has mostly been pursued by cross-breeding leptin-deficient (ob/ob) or leptin receptor-deficient $(\mathrm{db} / \mathrm{db})$ mice with atherosclerotic ApoE ${ }^{-/-}$[9-11] and LDLR ${ }^{-/-}[9,12]$ mice. Recently the ob/ob mouse was cross-bred also with $\mathrm{ApoE}^{-/-}$ $\mathrm{ApoB}^{100 / 100}$ and $\mathrm{LDLR}^{-/-} \mathrm{ApoB}^{100 / 100}$ mice [13], resulting in promising models of metabolic syndrome. However, a major shortcoming in these models is that the perturbation of glucose metabolism does not appear to affect atherosclerosis without concomitant elevations in plasma lipid levels $[14,15]$. Also data about their cardiac phenotype is scarce - there are only a few studies on ventricular function of ob/ob/LDLR ${ }^{-1-}$ mice [16-18], although differentiating the effects of diabetes from those of hypercholesterolemia cannot be done without comparisons to non-diabetic hypercholesterolemic mice. In addition, the status of coronary artery atherosclerosis and its relation to cardiac function have not been studied in any comparable models of diabetic macrovascular disease.

We have previously developed a mouse model of diabetic macroangiopathy, where mice overexpressing IGFII in pancreatic beta cells [19] in hypercholesterolemic $\mathrm{LDLR}^{-/-} \mathrm{ApoB}^{100 / 100}$ background represent hyperglycemia, insulin resistance and mild hyperinsulinemia without concomitant changes in plasma lipid levels [20]. To study the cardiac phenotype of hypercholesterolemic $\mathrm{LDLR}^{-/-} \mathrm{ApoB}^{100 / 100}$ mice and to see if it is impaired by diabetes, we now evaluated the extent of coronary artery disease (CAD) and its effects on myocardial perfusion, left ventricular function and cardiac reserve in vivo. Senescent animals were used to simulate the respective human patient population, and $\mathrm{C} 57 \mathrm{Bl} / 6$ mice were included to control the effects of aging and high fat diet.

\section{Methods}

\section{Animals}

We have previously developed IGF-II/LDLR ${ }^{-/-} \mathrm{ApoB}^{100 /}$ 100 mouse as a model of diabetic macroangiopathy [20]. In the present study, IGF-II negative $\mathrm{LDLR}^{-/-} \mathrm{ApoB}^{100 / 100}$ littermates served as controls and we also included matched $\mathrm{C} 57 \mathrm{Bl} / 6 \mathrm{~J}$ mice to control the effects of aging and high-fat diet. Mice ( $\mathrm{n}=12-15 /$ strain) were fed $a d$ libitum with a normal chow diet (R36, Lactamin, Sweden). At the age of 15 months mice were put on a high fat Western diet (TD 88173, Harlan Teklad: 42\% of calories from fat and $0.15 \%$ from cholesterol) for three months, thus the animals were 18 months old at the time of analysis. Both female and male mice were used in this study. Experiments were approved by the National Experimental Animal Board.

\section{Metabolic analyses}

Glucose tolerance test (GTT) and blood glucose measurements were carried out in mice fasted overnight (15 h) as described [20]. Triglycerides and total cholesterol were determined from fasting plasma samples as described [21].

\section{Echocardiography}

Transthoracic echocardiography was performed in isoflurane anesthetized mice at rest and after inotropic stimulation with dobutamine using a high-resolution imaging system for small animals (Vevo 770, VisualSonics Inc., Canada) equipped with a high-frequence ultrasound probe (RMV-707B) as described [22]. Left ventricular (LV) dimensions and wall thicknesses were determined from parasternal short axis M-mode images. Ejection fraction (EF), fractional shortening (FS), LV volume and LV mass were calculated by Vevo770 software. EF was determined by using the Teicholz formula. The data represent averaged values of 3 cardiac cycles. The $\beta$-adrenoceptor agonist dobutamine $(1 \mu \mathrm{g} / \mathrm{g})$ was injected intraperitoneally $(n=5-6 /$ strain $)$ and echocardiography was performed at baseline and 1, 5, 10 and 15 minutes after injection. The values of individual peak response were used. Regional LV wall motion was evaluated before and after dobutamine stress from electrocardiogram kilohertz-based visualization (EKVTM) cine loops. A 12-segment model on two levels of short axis views (mid-ventricle and apical) comprising of 6 wall segments (anterior, anterolateral, inferolateral, inferior, and inferoseptal) was used. Wall motion was scored $1=$ normal, 2 = hypokinetic, 3 = akinetic and $4=$ dyskinetic, and a score index was calculated as the sum of scores divided by the total number of segments. In addition to the regional evaluation of the myocardium in dobutamine stress echocardiography, LV wall motion was also assessed in all animals ( $\mathrm{n}=11-13 /$ strain) from long-axis cine view.

\section{Myocardial perfusion}

Myocardial perfusion was quantified as described [22]. Briefly, perfusion was measured with Cadence ${ }^{\mathrm{TM}}$ contrast pulse sequence (CPS) ultrasound by Acuson Sequoia C256 using 15L8 probe (Siemens Medical Solutions, USA) and a second generation microbubble contrast agent (SonoVue, Bracco Diagnostics Inc., USA) administered as a $50 \mu \mathrm{l}$ bolus via tail vein. Datapro (v2.13, Noesis SA, France) was used to quantify CPS signal intensities.

\section{Histology}

Mice were sacrificed with carbon dioxide and perfused with phosphate-buffered saline. Tissue samples were immersion-fixed with 4\% paraformaldehyde ( $\mathrm{pH}$ 7.4). Aortas were embedded in paraffin after which cross-sectional lesion areas from the sinus level [21] and lesion calcification [20] were quantified as described. To 
quantify coronary artery atherosclerosis the maximal luminal narrowing was measured as a percentage from the area enclosed by the internal elastic lamina in serial cross-sections [23]. Vascular remodeling ratio was calculated by dividing individual cross-sectional vessel areas by the average area of the $\mathrm{C} 57 \mathrm{Bl} / 6 \mathrm{~J}$ controls, and classified as inward $(<0.95)$, absent $(0.95-1.05)$ or outward remodeling (>1.05) [24]. Myocardial fibrosis was quantified from Masson Trichome stained serial sections from the level of basal ventricle to apex. Analyses were performed in a blinded fashion using AnalySIS software (Soft Imaging System GmbH).

\section{Electron microscopy}

Tissue specimens were fixed overnight in $2.5 \%$ glutaraldehyde, treated with $1 \%$ osmium tetroxide, dehydrated and embedded in LX-112 resin and polymerized. The 60-70 $\mathrm{nm}$ sections were contrasted with uranyl acetate and lead citrate and examined by transmission electron microscopy (JEM 1200EX, JEOL Ltd. Japan).

\section{Statistical analysis}

Student's paired t-test was used for analyzing individual response to dobutamine stress, one-way ANOVA with Bonferroni's post test was used for detecting differences between the mouse strains and ANOVA of repeated measures was applied to analyze the results of GTT. P < 0.05 was considered significant. Numerical values are shown as mean \pm standard deviation (SD). Statistical analyses were performed using GraphPad Prism 4.0.

\section{Results}

\section{Basic metabolic parameters}

Metabolic parameters are presented in Table 1. Interestingly, body weight tended to be higher in C57Bl/6J mice, especially in males. Nevertheless, it did not reflect on other metabolic factors such as blood glucose or glucose tolerance - the IGF-II/LDLR ${ }^{-/-} \mathrm{ApoB}^{100 / 100}$ mice showed both fasting hyperglycemia $(8.2 \pm 3.0 \mathrm{mmol} / \mathrm{l})$ and impaired glucose tolerance in intraperitoneal GTT (2-hour post-glucose load $14.7 \pm 6.0 \mathrm{mmol} / \mathrm{l}$ ) compared to $\mathrm{LDLR}^{-/-} \mathrm{ApoB}^{100 / 100}$ and $\mathrm{C} 57 \mathrm{Bl} / 6 \mathrm{~J}$ mice (Table 1 Figure 1). Due to common genetic background and high fat diet the total cholesterol levels were significantly higher, although equal, in both $\mathrm{LDLR}^{-/-} \mathrm{ApoB}^{100 / 100}$ and IGF-II/LDLR ${ }^{-/-}$ApoB $^{100 / 100}$ mice $(25.5 \pm 7.9$ and $27.8 \pm$ $5.0 \mathrm{mmol} / \mathrm{l}$, respectively) compared to $\mathrm{C} 57 \mathrm{Bl} / 6 \mathrm{~J}$ controls $(3.9 \pm 1.4 \mathrm{mmol} / \mathrm{l})$. However, in triglycerides there was no difference between $\mathrm{C} 57 \mathrm{Bl} / 6 \mathrm{~J}$ and $\mathrm{LDLR}^{-/-} \mathrm{ApoB}^{100 / 100}$ mice $(1.0 \pm 0.3$ and $1.1 \pm 0.3 \mathrm{mmol} / \mathrm{l}$, respectively), whereas in diabetic IGF-II/LDLR ${ }^{-/-} \mathrm{ApoB}^{100 / 100}$ mice the concentration was slightly elevated $(1.5 \pm 0.5 \mathrm{mmol} / \mathrm{l}, P$ $<0.05)$.

\section{Atherosclerosis in hypercholesterolemic mice is accompanied by compensatory vascular remodeling and aggravated by calcification in IGF-II/LDLR ${ }^{-/}$ApoB $^{100 / 100}$ mice}

Atherosclerosis was quantified from serial aortic crosssections from the sinus level. No lesions were detected in aortas of $\mathrm{C} 57 \mathrm{Bl} / 6 \mathrm{~J}$ mice, whereas in $\mathrm{LDLR}^{-1-} \mathrm{ApoB}^{100 /}$ 100 and IGF-II/LDLR ${ }^{-1-} \mathrm{ApoB}^{100 / 100}$ mice lesion areas were $61.1 \pm 8.7 \%$ and $60.0 \pm 7.9 \%$ of the total aortic area, respectively (Figure 2A, D). Although the diabetic background did not affect lesion size per se, there was more intimal calcification in IGF-II/LDLR ${ }^{-/-} \mathrm{ApoB}^{100 / 100}$ mice $(18.2 \pm 17.3 \%$ of plaque area) compared to hypercholesterolemic $\mathrm{LDLR}^{-/-} \mathrm{ApoB}^{100 / 100}$ mice $(8.6 \pm$ $6.1 \%$ of plaque area) or $\mathrm{C} 57 \mathrm{Bl} / 6 \mathrm{~J}$ mice (no calcification detected) (Figure 2B, D). Atherosclerosis was associated with compensatory enlargement of the vessel area with a vascular remodeling ratio of $2.63 \pm 0.32$ in $\mathrm{LDLR}^{-/}$ $\mathrm{ApoB}^{100 / 100}$ and $2.79 \pm 0.28$ in IGF-II/LDLR ${ }^{-1-} \mathrm{ApoB}^{100 /}$ 100 mice compared to $\mathrm{C} 57 \mathrm{Bl} / 6 \mathrm{~J}$ mice (Figure 2C). Consequently, despite extensive atherosclerosis, lumen areas were not decreased in $\mathrm{LDLR}^{-/-} \mathrm{ApoB}^{100 / 100}(690.3 \pm$

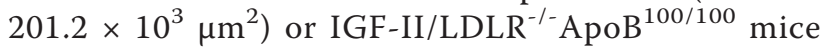
$\left(756.4 \pm 149.9 \times 10^{3}{\mu \mathrm{m}^{2}}^{2}\right)$ compared to non-atherosclerotic C57Bl/6J controls $\left(716.4 \pm 112.9 \times 10^{3} \mu \mathrm{m}^{2}\right)$.

\section{Severe coronary artery stenosis in hypercholesterolemic mice}

Significant stenosis was observed in ostial parts of coronary arteries in $\mathrm{LDLR}^{-/-} \mathrm{ApoB}^{100 / 100}$ and IGF-II/LDLR ${ }^{-/-}$ ApoB ${ }^{100 / 100}$ mice. The stenosis was most prominent in the left coronary artery, which was narrowed in all studied $\mathrm{LDLR}^{-/-} \mathrm{ApoB}^{100 / 100}$ and IGF-II/LDLR ${ }^{-/-} \mathrm{ApoB}^{100 / 100}$ mice with average luminal stenosis of $79.4 \pm 14.3 \%$ and $85.0 \pm 6.5 \%$, respectively (Figure $3 \mathrm{~A}, \mathrm{C}$ ). This was accompanied with outward remodeling: compared to $\mathrm{C} 57 \mathrm{Bl} / 6 \mathrm{~J}$, remodeling ratio of the left coronary artery was $3.17 \pm 2.65$ in $\mathrm{LDLR}^{-/-} \mathrm{ApoB}^{100 / 100}$ and $3.94 \pm 2.08$ in IGF-II/LDLR ${ }^{-/-} \mathrm{ApoB}^{100 / 100}$ mice (Figure 3B). However, in spite of the vessel enlargement, significant decrease of the left coronary artery lumen area was present in both $\mathrm{LDLR}^{-/-} \mathrm{ApoB}^{100 / 100}\left(8.3 \pm 5.8 \times 10^{3} \mu \mathrm{m}^{2}, P\right.$ $<0.01)$ and IGF-II/LDLR ${ }^{-/-} \mathrm{ApoB}^{100 / 100}$ mice $(9.8 \pm 4.9 \times$ $\left.10^{3} \mu^{2}, P<0.05\right)$ compared to $C 57 \mathrm{Bl} / 6 \mathrm{~J}$ controls $(19.3$ $\pm 10.0 \times 10^{3} \mu \mathrm{m}^{2}$ ). In the right coronary artery, $22 \%$ of $\mathrm{LDLR}^{-/-} \mathrm{ApoB}^{100 / 100}$ and $50 \%$ of IGF-II/LDLR ${ }^{-/-} \mathrm{ApoB}^{100 /}$ ${ }^{100}$ mice showed mean stenosis of $76.1 \pm 8.2 \%$ and 86.2 $\pm 7.6 \%$, respectively (Figure $3 \mathrm{~A}$ ). Stenosis of the septal artery was detected in $50 \%$ of mice in both groups with average stenosis of $92.0 \pm 10.0 \%$ in $\mathrm{LDLR}^{-1-} \mathrm{ApoB}^{100 / 100}$ and $74.7 \pm 31.6 \%$ in IGF-II/LDLR ${ }^{-/-} \mathrm{ApoB}^{100 / 100}$ mice (Figure 3A). Despite severe atherosclerosis in the proximal coronary arteries, no lesions were detected in the 
Table 1 Metabolic parameters, echocardiographic measurements and myocardial perfusion

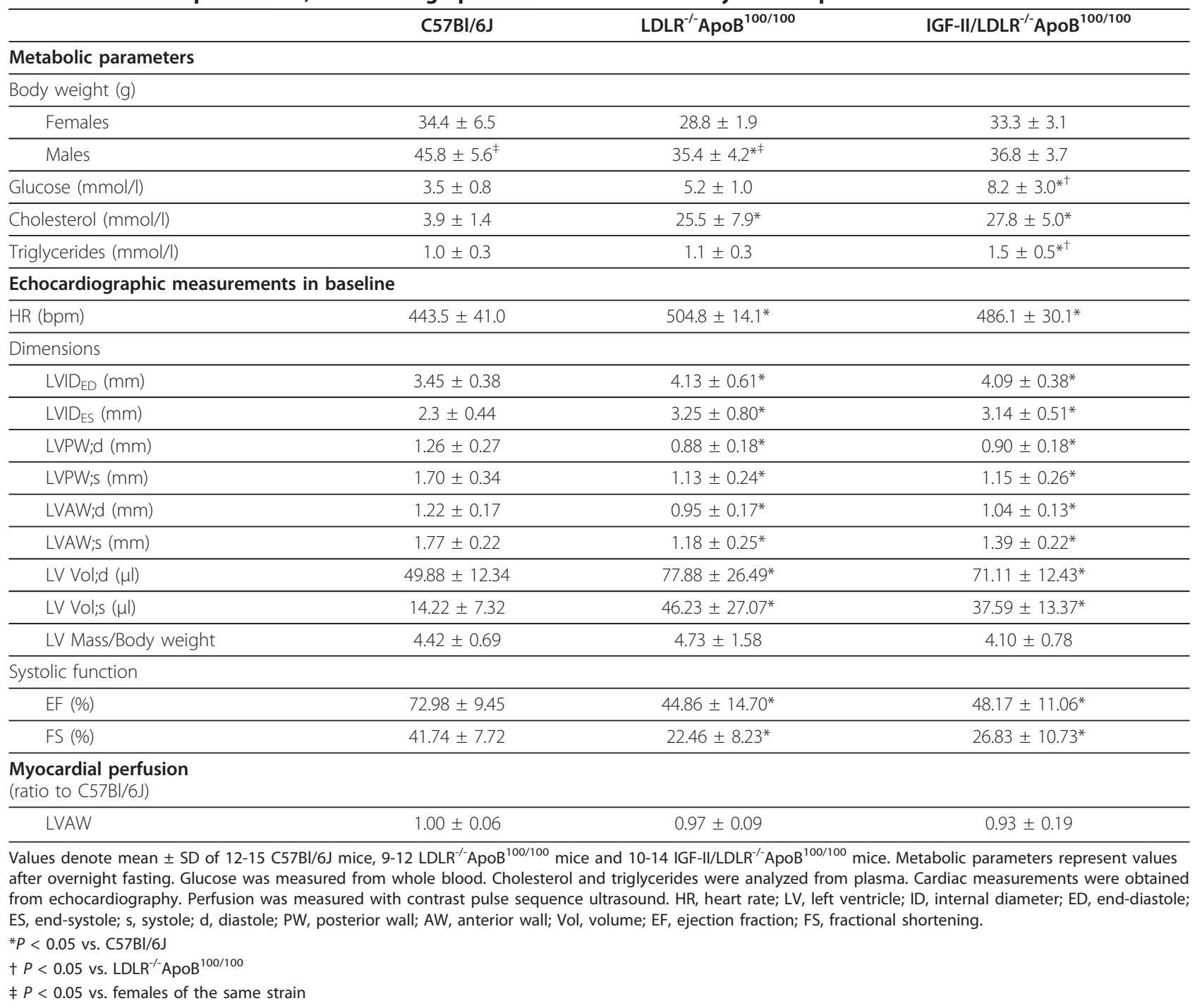

distal parts. In $\mathrm{C} 57 \mathrm{Bl} / 6 \mathrm{~J}$ mice no lesion formation was observed in any part of the coronary tree.

\section{Coronary atherosclerosis leads to left ventricular dysfunction}

Echocardiography was performed to examine in vivo LV function. LV chamber dimensions, anterior wall (AW) and posterior wall $(\mathrm{PW})$ thicknesses and LV mass were obtained from M-mode images (Table 1). Compared to C57Bl/6J mice, LV end-diastolic and end-systolic diameters were significantly increased in both $\mathrm{LDLR}^{-/-}$ $A p o B^{100 / 100}$ and IGF-II/LDLR ${ }^{-/-}$ApoB ${ }^{100 / 100}$ mice. LV dilatation was demonstrated by increased LV end-diastolic and end-systolic volumes and dilatation was most pronounced in $\mathrm{LDLR}^{-/-} \mathrm{ApoB}^{100 / 100}$ mice. Related to LV dilatation, reduced thickness of both posterior and anterior $\mathrm{LV}$ wall was evident in both $\mathrm{LDLR}^{-/-} \mathrm{ApoB}^{100 / 100}$ and IGF-II/LDLR ${ }^{-/-}$ApoB ${ }^{100 / 100}$ mice. In line with the impaired cardiac function, resting heart rate was higher in $\mathrm{LDLR}^{-/-} \mathrm{ApoB}^{100 / 100}$ and IGF-II/LDLR ${ }^{-/-} \mathrm{ApoB}^{100 / 100}$ mice compared to $\mathrm{C} 57 \mathrm{Bl} / 6 \mathrm{~J}$ controls.

LV systolic function was evaluated with the Teicholz method of the EF and FS in M-mode images. Both were significantly reduced in $\mathrm{LDLR}^{-/-} \mathrm{ApoB}^{100 / 100}$ and IGF-II/ $\mathrm{LDLR}^{-/-} \mathrm{ApoB}{ }^{100 / 100}$ mice depicting severe contractile dysfunction, whereas $\mathrm{C} 57 \mathrm{Bl} / 6 \mathrm{~J}$ controls showed normal cardiac function (Table 1). In visual evaluation of the parasternal long axis 2-dimensional EKV ${ }^{\mathrm{TM}}$ cine loops [see Additional files 1, 2 \&3], LVAWs of the C57Bl/6J controls were mostly normokinetic with only mild hypokinesia noted in two animals and a dyskinetic area in one animal. Impaired wall motion with hypokinesia was common in $\mathrm{LDLR}^{-/-} \mathrm{ApoB}^{100 / 100}$ (in 10/13 mice, 76.9\%) and IGF-II/LDLR ${ }^{-1-} \mathrm{ApoB}^{100 / 100}$ mice (in 8/11 mice, 


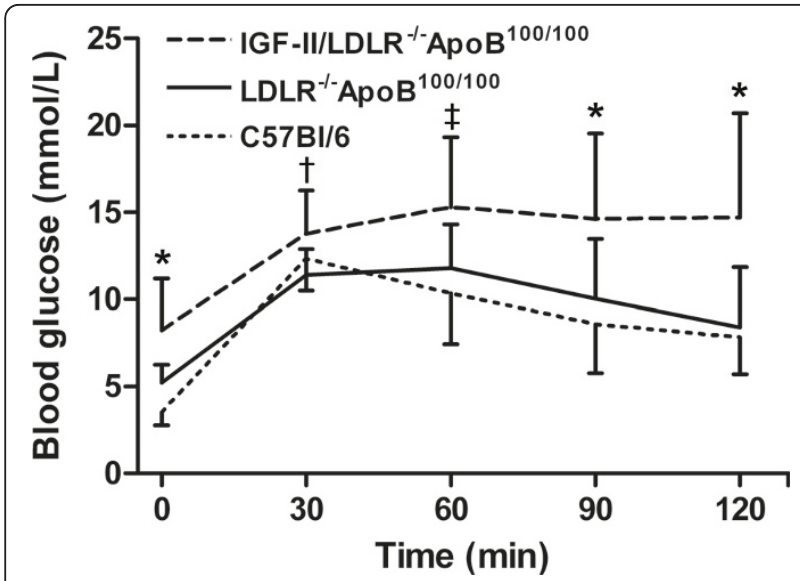

Figure $1 \mathrm{IGF}-\mathrm{II}_{\text {LDLR }}{ }^{-/} \mathrm{ApoB}^{100 / 100}$ mice show elevated fasting glucose and glucose intolerance in an intraperitoneal GTT. Values denote mean \pm SD of $9\left(\mathrm{LDLR}^{-/-} \mathrm{ApoB}{ }^{100 / 100}\right)$ or $12(\mathrm{C} 57 \mathrm{BI} / 6 \mathrm{~J}$ and IGF-II/LDLR $\left.{ }^{-/-} \mathrm{ApoB}^{100 / 100}\right)$ 18-month-old mice. ${ }^{*} P<0.05$ in IGFII/LDLR ${ }^{-/-} A p o B^{100 / 100}$ versus C57BI/6J and LDLR LPoB $^{100 / 100}$ mice, $†$ $P<0.05$ between IGF-II/LDLR ${ }^{-/-} A p o B^{100 / 100}$ and LDLR $^{-/-} A p o B^{100 / 100}$ mice, $\neq P<0.05$ between IGF-II/LDLR ${ }^{-/-}$ApoB ${ }^{100 / 100}$ and $C 57 \mathrm{BI} / 6 \mathrm{~J}$ mice.

72.7\%), and akinetic areas were observed in altogether four animals: one $\mathrm{LDLR}^{-/-} \mathrm{ApoB}^{100 / 100}$ and three IGF-II/ $\mathrm{LDLR}^{-/-} \mathrm{ApoB}^{100 / 100}$ mice. Animals with severe LV wall dysfunction had high aortic lesion area (> 70\%), calcified plaques $(4-12 \%$ of plaque area), severe coronary artery stenosis (> 93\% occlusion in left coronary artery) and LV ejection fraction of 18 - 41\%. Despite of the detected akinesia in the echocardiograms there were neither increased echogenicity of the affected area, nor histological observations of increased fibrosis referring to myocardial infarction scar in Masson-Trichrome stained serial sections (data not shown). Moreover, although the overall mortality did not differ between mouse models, one animal in both $\mathrm{LDLR}^{-/-} \mathrm{ApoB}^{100 / 100}$ and IGF-II/ $\mathrm{LDLR}^{-/-} \mathrm{ApoB}^{100 / 100}$ groups collapsed and died during isoflurane anesthesia.

\section{Cardiac reserve is preserved but reduced in atherosclerotic mice}

To examine the myocardial viability, dobutamine stress echocardiography was performed to evaluate cardiac reserve. The timepoint of individual peak response after dobutamine administration varied between 5 and 15 minutes and analyses were performed from the maximal response values (Table 2). Dobutamine-induced chronotropic responses correlated inversely with baseline heart rates: $\mathrm{C} 57 \mathrm{Bl} / 6 \mathrm{~J}$ mice with the lowest resting heart rate showed the highest increase of $13.2 \pm 8.5 \%(P=0.043$ compared to baseline), whereas in IGF-II/LDLR ${ }^{-/}$ $\mathrm{ApoB}^{100 / 100}$ mice the heart rate increased $9.9 \pm 4.9 \%(P$ $=0.011)$ and in $\operatorname{LDLR}^{-/-} \mathrm{ApoB}^{100 / 100}$ mice with the highest resting heart rate the increase was only $6.2 \pm$ 6.5\% $(P=0.070)$.

In parallel, significant enhancement in systolic function $(\triangle \mathrm{EF}, \triangle \mathrm{FS})$ was seen in all strains and increased myocardial contractility, depicted by increased thickness of the LV walls, was as well observed (Table 2 Figure 4). Furthermore, both diastolic and systolic LV dimensions decreased significantly. Although rather equal in percentage, the overall response to dobutamine was diminished in relation to baseline values in both diabetic and nondiabetic $\mathrm{LDLR}^{-/-} \mathrm{ApoB} \mathrm{B}^{100 / 100}$ mice. However, all mice responded to the $\beta$-adrenergic stimulation and their wall motion improved (Figure 4 ). Due to a limited sample size ( $\mathrm{n}=5-6 /$ strain), change in the wall motion score index was statistically significant only in $\mathrm{LDLR}^{-/-}$ ApoB $^{100 / 100}$ mice $(P<0.001)$. This was possibly influenced also by their significantly poorer baseline score $(1.70 \pm 0.12)$ compared to IGF-II/LDLR ${ }^{-/-} \mathrm{ApoB}^{100 / 100}$ $(1.26 \pm 0.17, P<0.01)$ and $\mathrm{C} 57 \mathrm{Bl} / 6 \mathrm{~J}$ mice $(1.14 \pm 0.20$, $P<0.001)$.

\section{Myocardial perfusion correlates with the atherosclerotic burden}

Measured with contrast pulse sequence ultrasound, there were no statistically significant differences in LVAW perfusion between the groups (Table 1). However, a trend towards decreased myocardial perfusion was seen in $\mathrm{LDLR}^{-/-} \mathrm{ApoB}^{100 / 100}$ and IGF-II/LDLR ${ }^{-/-}$ ApoB $^{100 / 100}$ mice.

\section{Ultrastructural analysis of myocardium reveals degenerative changes in hypercholesterolemic mice}

In electron microscopy analysis ventricular myocardium showed degenerative changes (Figure 5). Cardiomyocytes with impaired cytoarchitecture, autophagosomes, decreased number of myofibrils and increased interfibrillar space with collagen fibrils, irregularly shaped dense bodies, myelin figures and focal deposits of glycogen were observed. Mitochondria were polymorphic and often doughnut-like. The changes were present in both $\mathrm{LDLR}^{-/-} \mathrm{ApoB}^{100 / 100}$ and IGF-II/LDLR ${ }^{-/-} \mathrm{ApoB}^{100 / 100}$ mice.

\section{Discussion}

In the present study the effects of type 2 diabetes on coronary artery disease and cardiac function were investigated in 18-month-old mice after three months of Western diet. We found notable stenosis in proximal coronary arteries in both $\mathrm{LDLR}^{-/-} \mathrm{ApoB}^{100 / 100}$ and diabetic IGF-II/LDLR ${ }^{-/-} \mathrm{ApoB}^{100 / 100}$ mice and the stenoses were most severe in the left coronary artery, which was significantly narrowed in all animals of these groups despite compensatory vessel remodeling. Since type 2 diabetes increases significantly the risk of coronary 


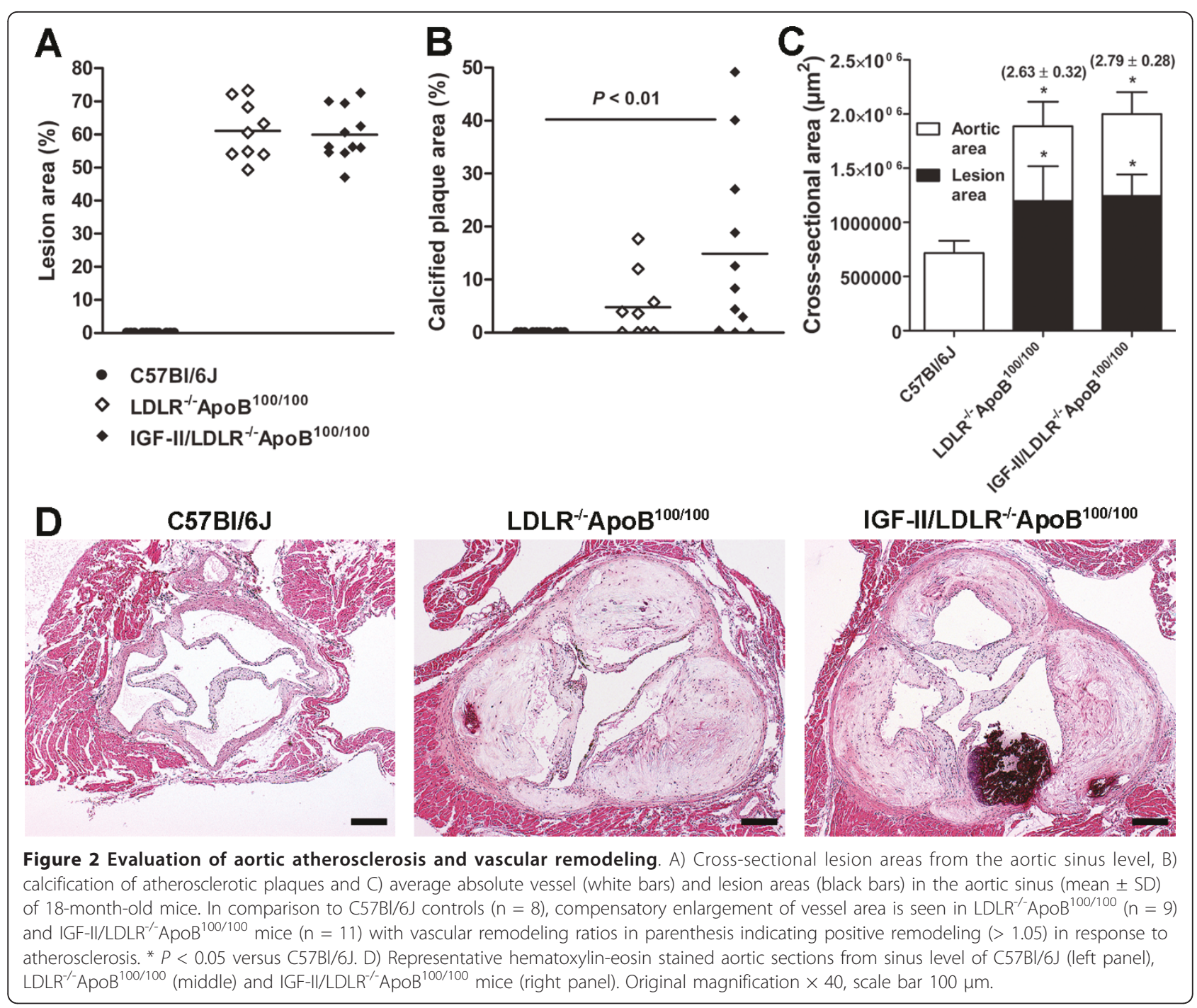

events [2,25], we wanted to study if the cardiac outcome would be worse in the diabetic animals. Regardless of increased intimal calcification in aortic lesions of the IGF-II/LDLR ${ }^{-1-}$ ApoB ${ }^{100 / 100}$ mice, diabetes did not lead to a worsened $\mathrm{CAD}$ compared to hypercholesterolemic $\mathrm{LDLR}^{-/-} \mathrm{ApoB}^{100 / 100}$ mice. Also LV function was equally impaired in both hypercholesterolemic mouse strains compared to age- and diet-matched $\mathrm{C} 57 \mathrm{Bl} / 6 \mathrm{~J}$ mice. Based on these findings the impaired cardiac function in IGF-II/LDLR ${ }^{-/-}$ApoB $^{100 / 100}$ mice does not seem to be related to diabetes. This is likely subsequent to the high plasma cholesterol levels of the $\mathrm{LDLR}^{-/-} \mathrm{ApoB}^{100 / 100}$ background in both models, since it is widely recognized that cholesterol is the main driving force behind atherogenesis in mice. However, because the cholesterol levels in our study were equal in diabetic and non-diabetic $\mathrm{LDLR}^{-/-} \mathrm{ApoB}{ }^{100 / 100}$ mice, detecting the effects of diabetes is possible, whereas the diabetes-induced elevation in plasma lipids seen in most models of diabetic atherosclerosis hampers dissecting the contribution of other metabolic factors on cardiovascular outcome [15].

Although genetically-modified mouse models of hypercholesterolemia are widely used in cardiovascular research [26,27], the status of coronary arteries and potential manifestation of myocardial infarction have been studied to a lesser extent. In the commonly used $\mathrm{LDLR}^{-1-}$ mice CAD seems to be absent even if atherogenic diet is used [28]. Lesions in coronary arteries and myocardial fibrosis were described in Western diet fed $\mathrm{ApoE}^{-1-}$ mice shortly after the model was generated [29], but since then controversial results have been reported: coronary artery occlusion and subsequent evidence of apical infarction are found by some [30], whereas in other studies the coronary arteries are found to be totally clean [31] or lesions are seen only in proximal parts of the arteries without signs of infracted 


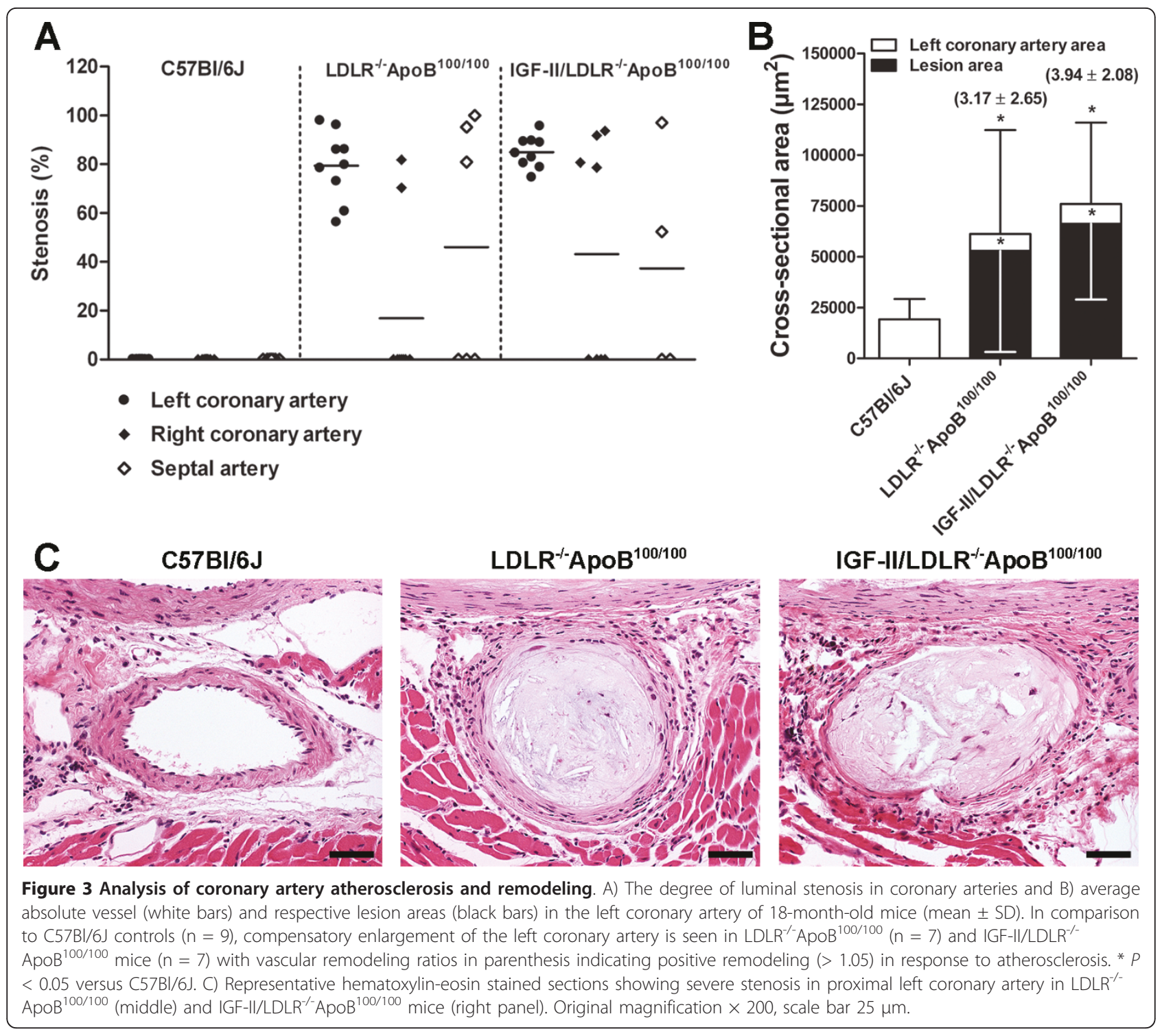

Table 2 Dobutamine stress induced changes in echocardiographic parameters

\begin{tabular}{|c|c|c|c|}
\hline$\%$ & C57BI/6J & LDLR $^{-/-}$ApoB $^{100 / 100}$ & IGF-II/LDLR ${ }^{-/}$ApoB $^{100 / 100}$ \\
\hline$\overline{\Delta H R}$ & $13.22 \pm 8.45(0.043)$ & $6.19 \pm 6.52(0.070)$ & $9.86 \pm 4.93(0.011)$ \\
\hline$\Delta \mathrm{EF}$ & $14.87 \pm 4.51(0.001)$ & $16.83 \pm 1.52(<0.0001)$ & $16.79 \pm 8.53(0.001)$ \\
\hline$\overline{\Delta F S}$ & $15.48 \pm 6.00(0.005)$ & $11.91 \pm 2.18(0.003)$ & $13.74 \pm 7.44(0.0145)$ \\
\hline$\overline{\Delta L V I D_{E D}}$ & $-9.4 \pm 4.5(0.009)$ & $-12.7 \pm 6.7(0.016)$ & $-9.3 \pm 3.7(0.032)$ \\
\hline$\triangle \mathrm{LVID} \mathrm{ES}_{\mathrm{ES}}$ & $-31.9 \pm 11.1(0.002)$ & $-24.6 \pm 6.8(0.001)$ & $-24.9 \pm 13.0(0.017)$ \\
\hline$\triangle \mathrm{LVPW} ; \mathrm{d}$ & $18.0 \pm 2.9(0.099)$ & $19.6 \pm 8.4(0.006)$ & $18.5 \pm 11.3(0.021)$ \\
\hline$\triangle \mathrm{LLVW} ; \mathrm{S}$ & $37.4 \pm 19.1(0.184)$ & $29.7 \pm 7.9(0.0004)$ & $28.3 \pm 13.9(0.004)$ \\
\hline$\overline{\Delta L V A W ; d}$ & $26.7 \pm 22.0(0.863)$ & $23.0 \pm 25.7(0.078)$ & $28.0 \pm 12.0(0.005)$ \\
\hline$\triangle \mathrm{LVAW} ; \mathrm{S}$ & $32.3 \pm 10.9(0.001)$ & $26.6 \pm 15.6(0.010)$ & $28.0 \pm 16.6(0.004)$ \\
\hline$\Delta \mathrm{LV}$ Vol;d & $-20.5 \pm 9.6(0.009)$ & $-25.5 \pm 14.1(0.012)$ & $-20.7 \pm 7.6(0.006)$ \\
\hline$\overline{\Delta L V ~ V o l ; s}$ & $-61.1 \pm 16.8(0.002)$ & $-50.0 \pm 12.0(0.002)$ & $-51.6 \pm 19.2(0.012)$ \\
\hline
\end{tabular}




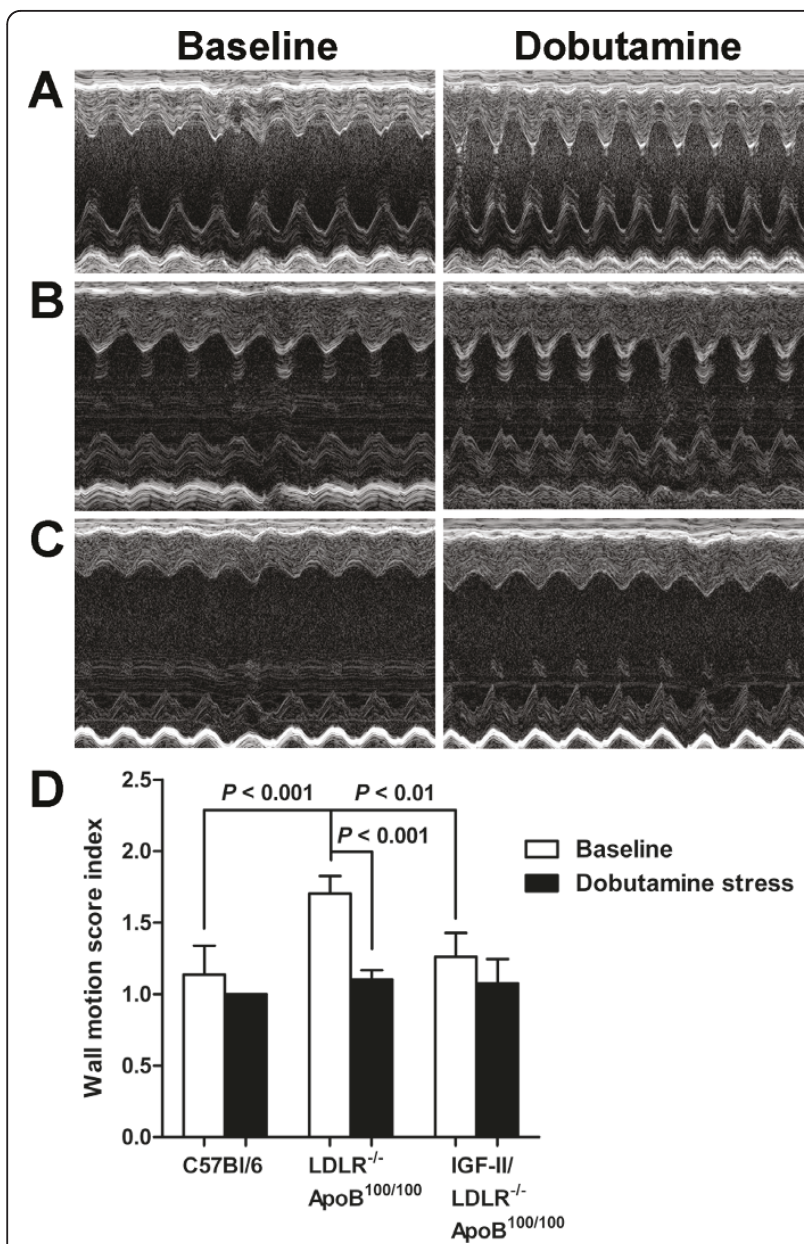

Figure 4 Dobutamine stress echocardiography. M-mode shortaxis views of the left mid-ventricle before and after $\beta$-adrenergic stimulation with dobutamine in an 18-month-old A) (57BI/6J, B) IGF-II/LDLR ${ }^{-/} A p o B^{100 / 100}$ and C) LDLR ${ }^{-/} A$ ApoB ${ }^{100 / 100}$ mouse. Compared to the C57BI/6J control, IGF-II/LDLR ${ }^{-/-} A p o B^{100 / 100}$ and $\mathrm{LDLR}^{-/} A \mathrm{poB}^{100 / 100}$ mice show reduced contractility. D) Regional wall motion analysis represents improvement of systolic function after dobutamine in all mouse strains, although statistically significant only in $\mathrm{LDLR}^{-1-} \mathrm{ApoB} \mathrm{B}^{100 / 100}$ mice. Results are mean $\pm \mathrm{SD}$ of $5\left(\mathrm{LDLR}^{-1-}\right.$ ApoB $^{100 / 100}$ and IGF-II/LDLR ${ }^{-/} A p o B^{100 / 100}$ ) or 6 animals (C57BI/6J).

myocardium [31-33]. The latter has been found also in the $\mathrm{LDLR}^{-/-} \mathrm{ApoB}^{100 / 100}$ mice by Saraste et al. [34] and verified in the present study. In the severely hypercholesterolemic ApoE $\mathrm{LDLR}^{-/-}$mice both distal coronary artery lesions and myocardial infarction have been reported [35,36]. The gravest phenotype is in double knockout mice lacking scavenger receptor class B type I (SR-BI) and ApoE - the mice die of CAD induced myocardial infarction by 8 weeks of age [37].

Positive or outward arterial remodeling is a compensatory increase in vessel size in order to maintain luminal area in atherosclerosis [38]. Whereas clinical studies on vascular remodeling in different disease states are
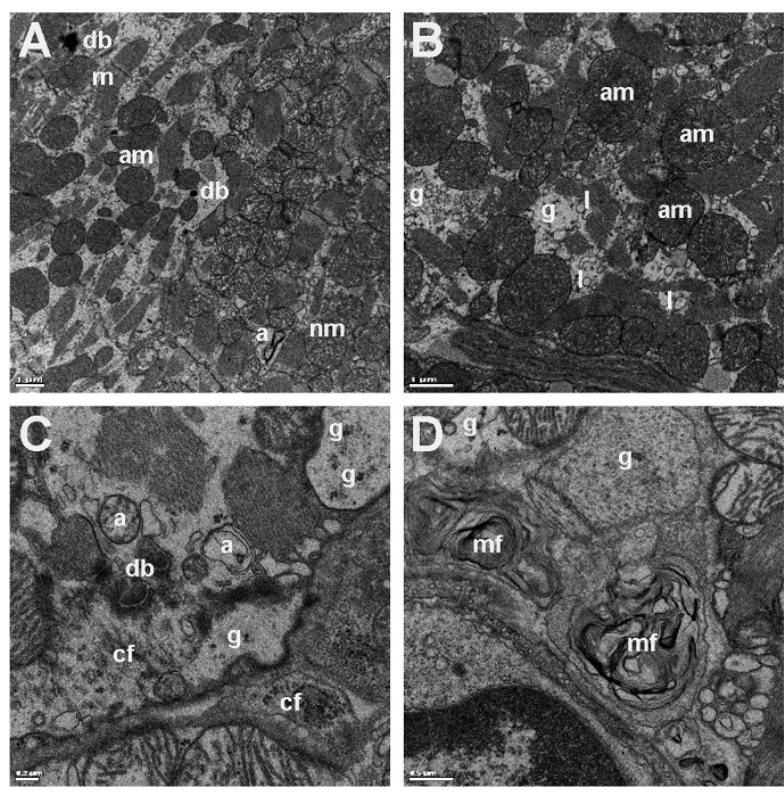

Figure 5 Representative images of ultrastructural changes found in $\mathrm{LDLR}^{-/-} A$ poB ${ }^{100 / 100}$ and IGF-II/LDLR ${ }^{-/-} A p o B^{100 / 100}$ mice.

A) On the left, impaired cytoarchitecture with increased interfibrillar space, dense bodies (db) and polymorphic and often doughnut-like mitochondria (am, abnormal mitochondria). Note autophagosome (a) in the preserved area. Nm, normal mitochondria; m, myofiber. B) Detail of the damaged area with increased number of enlarged abnormal mitochondria (am), lysosomes (I) and sparse glycogen deposits (g). C) Increased interfibrillar space filled with autophagosomes (a), dense bodies (db), collagen fibrils (cf) and glycogen deposits (g). D) Detail on myelin figures ( $\mathrm{mf}$ ) and glycogen deposits (g). Images are from IGF-II/LDLR ${ }^{-/} A p o B^{100 / 100}$ mice. Bars $1.0 \mu \mathrm{m}$ (A, B), $0.2 \mu \mathrm{m}(C)$ and $0.5 \mu \mathrm{m}(\mathrm{D})$.

abundant, less is known about it in experimental models, especially mice. Positive remodeling has been observed in aortic sinus [39] as well as in carotid, thoracic and abdominal aortas of $\mathrm{ApoE}^{-/-}$mice [24,40]. Consistent with this data, our results show enlargement of vessel areas in both aortic sinus and coronary arteries. In aortic sinus this compensatory remodeling resulted in maintenance of a lumen area equal to non-atherosclerotic C57Bl/6J controls, whereas in left coronary artery the lumen was significantly narrowed. Since stenosis was greater in coronary arteries $(\sim 80 \%)$ than in the aortic sinus ( $60 \%)$, this might reflect a similar observation made in humans: once certain threshold in plaque deposition is exceeded, further enlargement might not be possible and lumen area is compromised by the growing lesion [38]. To our knowledge, vascular remodeling has been previously studied neither in mouse coronary arteries nor in a model of diabetic atherosclerosis. Because of the increased risk for cardiac events in diabetes, this is a matter of interest. Association between positive remodeling and unstable lesions has been 
suggested $[41,42]$ and therefore it could be speculated that outward remodeling would be greater in diabetic patients with accelerated atherosclerosis and thus possibly also in the diabetic IGF-II/LDLR ${ }^{-/} \mathrm{ApoB}^{100 / 100}$ mice with a more inflammatory vascular phenotype and advanced lesions [20]. On the other hand, also negative remodeling could contribute to the increased incidence of cardiac events in diabetics. However, in the present study diabetes did not lead to either of these but the remodeling was equal compared to non-diabetic mice with similar atherosclerosis. Inconsistent findings have been done also in humans: both increased [43] and inadequate compensatory remodeling [44] have been detected with intravascular ultrasound, calling for more in-depth studies in experimental models.

Atherosclerosis as a progressive disease and aging is associated with general cardiovascular changes [45]. Compared to our former characterization of 15-monthold animals [20], older age of mice in the present study reflected as an analogous augmentation of atherosclerotic calcification in both diabetic and non-diabetic LDLR $^{-/-}$ $\mathrm{ApoB}^{100 / 100}$ mice. Also plasma triglyceride levels of the IGF-II/LDLR ${ }^{-/} A p o B^{100 / 100}$ mice were now higher than in $\mathrm{LDLR}^{-1-} \mathrm{ApoB}^{100 / 100}$ mice and could in theory contribute to increased calcification. However, this is unlikely, since the level was still in the normal range and numerically only marginally higher than in the $\mathrm{LDLR}^{-/-} \mathrm{ApoB}^{100 / 100}$ mice. In addition, in our previous study the situation was vice versa and yet there was more calcification in the IGF-II/LDLR ${ }^{-1-}$ ApoB $^{100 / 100}$ mice. Thus the difference in plasma triglycerides most probably describes natural fluctuation. Moreover, no significant correlation between lipid levels and level of calcification were noted. Therefore the physiological significance of minor changes in triglycerides is unlikely, especially in the presence of severe hypercholesterolemia.

Despite prominent stenosis in proximal coronary arteries and observed regional akinesia in LVAW of $\mathrm{LDLR}^{-1-} \mathrm{ApoB}^{100 / 100}$ and IGF-II/LDLR ${ }^{-/-} \mathrm{ApoB}^{100 / 100}$ mice, signs of myocardial infarction were not found. Thus, the observed severe LV dysfunction most likely results from adaptation to chronic hypoperfusion rather than acute ischemic events. In support of this the resting perfusion in LVAW was only slightly reduced, which is in line with the study observing reduced coronary flow reserve in old, Western diet fed $\mathrm{LDLR}^{-1-} \mathrm{ApoB}^{100 / 100}$ mice [34]. Cardiac functional reserve after dobutamine challenge was preserved, although depressed compared to $\mathrm{C} 57 \mathrm{Bl} / 6$ controls, indicating that the dysfunctional myocardium of $\mathrm{LDLR}^{-/-} \mathrm{ApoB}^{100 / 100}$ and IGF-II/LDLR $\mathrm{LP}^{-1-}$ $\mathrm{ApoB}^{100 / 100}$ mice was not scarred but viable. Dobutamine stress echocardiography is a feasible non-invasive method to gain information about cardiac function and capacity, and to predict reversibility of wall motion after revascularization [46]. In Apo: ${ }^{-1-}$ mice the cardiac functional reserve has been found to be reduced [47]. Also in diabetic $\mathrm{db} / \mathrm{db}[48]$ and ob/ob mice [18] the response to $\beta$-adrenergic stimulation has been shown to be decreased. So far the only study done in a mouse model of diabetic atherosclerosis showed impaired cardiac reserve in the ob/ob/LDLR ${ }^{-/-}$mice [18].

In patients with ischemic cardiomyopathy, hibernating myocardium is an important clinical entity with significant prognostic value when considering revascularization procedures. Myocardial hibernation is referred as a state of reduced contractile function in the setting of CAD that is reversible with revascularization. Interestingly, various results in the present study suggest myocardial hibernation: LV dysfunction distal to coronary stenosis, preserved inotropic reserve, absence of necrosis and minor reduction in myocardial perfusion. Also the ultrastructural findings in $\mathrm{LDLR}^{-/-} \mathrm{ApoB}^{100 / 100}$ and IGFII/LDLR ${ }^{-1-} \mathrm{ApoB}^{100 / 100}$ mice support the possibility of hibernation, since the morphological hallmarks of chronic myocardial hibernation include signs of atrophy (especially contractile myofibrils and loss of cardiomyocytes) and degenerative changes (disorganization of cytoskeleton, cellular debris in interstitium, increased collagen and glycogen) without necrosis [49]. As a limitation to the hypothesis of myocardial hibernation, some of the changes seen in $\mathrm{LDLR}^{-/-} \mathrm{ApoB}^{100 / 100}$ and IGF-II/LDLR ${ }^{-/-} \mathrm{ApoB}^{100 / 100}$ mice could be induced also by aging. However, there is a general lack of suitable animal models that has hampered the studies of myocardial hibernation. Because achieving reproducible and chronic partial coronary artery stenosis without infarction is technically very challenging, most experimental studies of myocardial hibernation have been done in larger animals, such as dogs and pigs $[49,50]$. The few mouse models reported are mainly based a short-term hypoperfusion [51] or genetic manipulation of e.g. myocardial angiogenesis [52]. Since chronic CAD and the resulting gradual intravascular occlusion are the major causes of ischemic cardiomyopathy in humans, it would be aspired to have them manifested also in the experimental animal model. Even if the model would not perfectly reproduce the human condition and the actual revascularization procedures as an affirmation of the hibernation are not technically feasible in mice, animal models can provide unique and valuable information.

\section{Conclusions}

Hypercholesterolemic LDLR $^{-/-}$ApoB ${ }^{100 / 100}$ mice with or without type 2 diabetes develop significant coronary artery atherosclerosis with positive arterial remodeling, severe left ventricular dysfunction with regional akinesia distal to coronary stenosis without signs of infarction, and represent preserved but reduced cardiac functional 
reserve and histological features referring to chronic myocardial hibernation. Hence, the cardiac outcome was not worsened by type 2 diabetes, probably because of dominant effect of severe hypercholesterolemia caused by the $\operatorname{LDLR}^{-1-}$ ApoB ${ }^{100 / 100}$ background. Since animal models describing type 2 diabetic macrovascular diseases are few, a thorough characterization of the vascular and cardiac phenotype of a mouse model combining common metabolic disorders, CAD and chronic myocardial hypoperfusion provides valuable information and offers a tool for experimental and translational research.

\section{Additional material}

Additional file 1: Long axis EKV'M ${ }^{\mathrm{TM}}$ cine loop of a C57BI/6J mouse Transthoracic echocardiography in C57BI/6J mouse was performed with Vevo 770 high-resolution imaging system. Long axis cine loops showed preserved normal function of the left ventricular walls. No atherosclerotic lesion development was seen in either aorta or coronary arteries. Ejection fraction was $79.9 \%$.

Additional file 2: Long axis EKVTMTM cine loop of a $\mathrm{LDLR}^{-/-} \mathrm{ApoB}^{100 /}$

100 mouse. Transthoracic echocardiography was performed with Vevo 770 high-resolution imaging system. Long axis electrocardiogram kilohertz-based visualization (EKVTMTM ) cine loops show a poor systolic function (ejection fraction 18.1\%) in a $L^{2} L_{R^{-/}} A p o B^{100 / 100}$ mouse. The left ventricle was dilated with anteroapical akinesia and hypokinetic posterior wall. The mouse had aortic cross-sectional lesion area of $73.3 \%$ with calcification and the left coronary artery was markedly stenosed (94.3\%).

\section{Additional file 3: Long axis EKVTM ${ }^{\mathrm{TM}}$ cine loop of an IGF-II/LDLR ${ }^{-1}$}

$A$ poB ${ }^{100 / 100}$ mouse. Transthoracic echocardiography was performed with Vevo 770 high-resolution imaging system. Long axis cine loops showed markedly reduced anteroapical wall motion in the left ventricle in an IGF-II/LDLR ${ }^{-/}$ApoB ${ }^{100 / 100}$ mouse, which presented calcified lesions covering $70 \%$ of the aortic lumen area at the sinus level and significant stenosis in both left and right coronary arteries (99.5\% and $93.2 \%$, respectively). Ejection fraction was reduced (41.2\%) compared to control C57Bl/6 mice.

\begin{abstract}
Abbreviations
A: autophagosome; am: abnormal mitochondria; ANOVA: analysis of variance; Apo: apolipoprotein; AW: anterior wall; CAD: coronary artery disease; $\mathrm{cf}$ : collagen fibril; CPS: contrast pulse sequence; d: diastole; db: dense bodies; ED: end-diastole; EF: ejection fraction; EKV: electrocardiogram kilohertz-based visualization; ES: end-systole; FS: fractional shortening; g: glycogen; GTT: glucose tolerance test; ID: internal diameter; IGF-II: insulin-like growth factorII; I: lysosome; LAX: lateral axis; LDLR: low density lipoprotein receptor; LV: left ventricle; m: myofiber; mf: myelin figures; Ml: myocardial infarction; nm: normal mitochondria; ND: not detected; PW: posterior wall; s: systole; SAX: sagittal axis; SD: standard deviation; SR-BI: scavenger receptor class B type l; Vol: volume.
\end{abstract}

\section{Acknowledgements}

This work was supported by the Finnish Academy; Finnish Foundation for Cardiovascular Research; Juselius Foundation; Finnish Cultural Foundation; Orion-Farmos Research Foundation; Aarne and Aili Turunen Foundation; European Regional Development Fund, Tekes - the Finnish Funding Agency for Technology and Innovation (decision no. 70048/08) and the European Union (SUMMIT EUFP7 Consortium grant 115006).

\section{Author details}

'Department of Biotechnology and Molecular Medicine at A.I. Virtanen Institute for Molecular Sciences, University of Eastern Finland, P.O. Box 1627, FI-70211 Kuopio, Finland. ${ }^{2}$ Heart Center, Kuopio University Hospital, P.O. Box
1777, Fl-70211 Kuopio, Finland. ${ }^{3}$ Pathology, Laboratory Centre, Tampere University Hospital, P.O. Box 2000, Fl-33521 Tampere, Finland. ${ }^{4}$ Center of Animal Biotechnology and Gene Therapy, Universitat Autònoma de Barcelona, E-08193 Bellaterra, Spain. ${ }^{5}$ Department of Medicine, University of Eastern Finland and Kuopio University Hospital, Fl-70210, Kuopio, Finland.

\section{Authors' contributions}

SEH conceived and designed the study, participated in echocardiography and perfusion studies, carried out histological, morphometrical and glucose metabolism analyses, performed statistical analyses and drafted the manuscript. MM participated in echocardiography and perfusion studies, and helped draft the manuscript. $\mathrm{MH}$ contributed in cardiac function analyses and interpretation, and helped draft the manuscript. PIM performed analysis of plasma lipids. EL participated in histological analyses and in vivo studies. IK performed electron microscopy analysis and helped draft the manuscript. FB and ML participated in study design and helped to draft the manuscript. SYH helped conceive the study, participated in its design and interpretation, and helped draft the manuscript. All authors read and approved the final manuscript.

\section{Competing interests}

The authors declare that they have no competing interests.

Received: 10 April 2011 Accepted: 30 June 2011

Published: 30 June 2011

\section{References}

1. Pyörälä K, Laakso M, Uusitupa M: Diabetes and atherosclerosis: an epidemiologic view. Diabetes Metab Rev 1987, 3:463-524.

2. Haffner SM, Lehto S, Rönnemaa T, Pyorala K, Laakso M: Mortality from coronary heart disease in subjects with type 2 diabetes and in nondiabetic subjects with and without prior myocardial infarction. $N$ Engl J Med 1998, 339:229-234.

3. Wu KK, Huan Y: Diabetic atherosclerosis mouse models. Atherosclerosis 2007, 191:241-249

4. UK Prospective Diabetes Study (UKPDS) Group: Intensive blood-glucose control with sulphonylureas or insulin compared with conventional treatment and risk of complications in patients with type 2 diabetes (UKPDS 33). Lancet 1998, 352:837-853.

5. Severson DL: Diabetic cardiomyopathy: recent evidence from mouse models of type 1 and type 2 diabetes. Can J Physiol Pharmacol 2004, 82:813-823.

6. Xu G, Takashi E, Kudo M, Ishiwata T, Naito Z: Contradictory effects of short- and long-term hyperglycemias on ischemic injury of myocardium via intracellular signaling pathway. Exp Mol Pathol 2004, 76:57-65.

7. Filippo CD, Marfella R, Cuzzocrea S, Piegari E, Petronella P, Giugliano D, Rossi F, D'Amico M: Hyperglycemia in Streptozotocin-Induced Diabetic Rat Increases Infarct Size Associated With Low Levels of Myocardial HO1 During Ischemia/Reperfusion. Diabetes 2005, 54:803-810.

8. Rodrigues B, Rosa KT, Medeiros A, Schaan BD, Brum PC, De Angelis K, Irigoyen MC: Hyperglycemia can delay left ventricular dysfunction but not autonomic damage after myocardial infarction in rodents. Cardiovasc Diabetol 2011, 10:26.

9. Gruen ML, Saraswathi V, Nuotio-Antar AM, Plummer MR, Coenen KR, Hasty AH: Plasma insulin levels predict atherosclerotic lesion burden in obese hyperlipidemic mice. Atherosclerosis 2006, 186:54-64.

10. Wendt T, Harja E, Bucciarelli L, Qu W, Lu Y, Rong LL, Jenkins DG, Stein G, Schmidt AM, Yan SF: RAGE modulates vascular inflammation and atherosclerosis in a murine model of type 2 diabetes. Atherosclerosis 2006, 185:70-77.

11. Wu KK, Wu TJ, Chin J, Mitnaul LJ, Hernandez M, Cai TQ, Ren N, Waters MG, Wright SD, Cheng K: Increased hypercholesterolemia and atherosclerosis in mice lacking both ApoE and leptin receptor. Atherosclerosis 2005, 181:251-259.

12. Hasty AH, Shimano H, Osuga J, Namatame I, Takahashi A, Yahagi N, Perrey S, lizuka Y, Tamura Y, Amemiya-Kudo M, Yoshikawa T, Okazaki H, Ohashi K, Harada K, Matsuzaka T, Sone H, Gotoda T, Nagai R, Ishibashi S, Yamada N: Severe hypercholesterolemia, hypertriglyceridemia, and atherosclerosis in mice lacking both leptin and the low density lipoprotein receptor. J Biol Chem 2001, 276:37402-37408. 
13. Lloyd DJ, McCormick J, Helmering J, Kim KW, Wang M, Fordstrom P, Kaufman SA, Lindberg RA, Veniant MM: Generation and characterization of two novel mouse models exhibiting the phenotypes of the metabolic syndrome: Apob48 $8^{-/}$Lep $^{\text {ob/ob }}$ mice devoid of ApoE or Ldlr. Am J Physiol Endocrinol Metab 2008, 294:E496-505.

14. Kennedy AJ, Ellacott KLJ, King VL, Hasty AH: Mouse models of the metabolic syndrome. Dis Model Mech 2010, 3:156-166.

15. Goldberg IJ, Dansky HM: Diabetic vascular disease: an experimental objective. Arterioscler Thromb Vasc Biol 2006, 26:1693-1701.

16. Verreth W, De Keyzer D, Pelat M, Verhamme P, Ganame J, Bielicki JK, Mertens A, Quarck R, Benhabiles N, Marguerie G, Mackness B, Mackness M, Ninio E, Herregods M, Balligand J, Holvoet P: Weight Loss-Associated Induction of Peroxisome Proliferator-Activated Receptor-\{alpha\} and Peroxisome Proliferator-Activated Receptor-\{gamma\} Correlate With Reduced Atherosclerosis and Improved Cardiovascular Function in Obese Insulin-Resistant Mice. Circulation 2004, 110:3259-3269.

17. Van den Bergh A, Vanderper A, Vangheluwe P, Desjardins F, Nevelsteen I, Verreth W, Wuytack F, Holvoet P, Flameng W, Balligand J, Herijgers P: Dyslipidaemia in type II diabetic mice does not aggravate contractile impairment but increases ventricular stiffness. Cardiovasc Res 2008, 77:371-379.

18. Van den Bergh A, Vangheluwe $P$, Vanderper $A$, Carmeliet $P$, Wuytack $F$, Janssens S, Flameng W, Holvoet P, Herijgers P: Food-restriction in obese dyslipidaemic diabetic mice partially restores basal contractility but not contractile reserve. Eur J Heart Fail 2009, 11:1118-1125.

19. Devedjian JC, George M, Casellas A, Pujol A, Visa J, Pelegrin M, Gros L, Bosch F: Transgenic mice overexpressing insulin-like growth factor-II in beta cells develop type 2 diabetes. J Clin Invest 2000, 105:731-740.

20. Heinonen SE, Leppänen $P$, Kholova I, Lumivuori H, Häkkinen S, Bosch F, Laakso M, Ylä-Herttuala S: Increased Atherosclerotic Lesion Calcification in a Novel Mouse Model Combining Insulin Resistance, Hyperglycemia, and Hypercholesterolemia. Circ Res 2007, 101:1058-1067.

21. Leppänen P, Koota S, Kholova I, Koponen J, Fieber C, Eriksson U, Alitalo K, Ylä-Herttuala S: Gene transfers of vascular endothelial growth factor-A, vascular endothelial growth factor-B, vascular endothelial growth factor$C$, and vascular endothelial growth factor-D have no effects on atherosclerosis in hypercholesterolemic low-density lipoprotein-receptor/ apolipoprotein B48-deficient mice. Circulation 2005, 112:1347-1352.

22. Huusko J, Merentie M, Dijkstra MH, Ryhänen M, Karvinen H, Rissanen TT, Vanwildemeersch M, Hedman M, Lipponen J, Heinonen SE, Eriksson U, Shibuya M, Ylä-Herttuala S: The effects of VEGF-R1 and VEGF-R2 ligands on angiogenic responses and left ventricular function in mice. CardiovasC Res 2010, 86:122-130.

23. Kragel A, Reddy S, Wittes J, Roberts W: Morphometric analysis of the composition of atherosclerotic plaques in the four major epicardial coronary arteries in acute myocardial infarction and in sudden coronary death. Circulation 1989, 80:1747-1756.

24. Pereira TM, Nogueira BV, Lima LC, Porto ML, Arruda JA, Vasquez EC, Meyrelles SS: Cardiac and vascular changes in elderly atherosclerotic mice: the influence of gender. Lipids Health Dis 2010, 9:87.

25. Juutilainen A, Lehto S, Rönnemaa T, Pyörälä K, Laakso M: Type 2 Diabetes as a "Coronary Heart Disease Equivalent". Diabetes Care 2005, 28:2901-2907.

26. Russell JC, Proctor SD: Small animal models of cardiovascular disease: tools for the study of the roles of metabolic syndrome, dyslipidemia, and atherosclerosis. Cardiovasc Pathol 2006, 15:318-330.

27. Hermansson A, Johansson DK, Ketelhuth DFJ, Andersson J, Zhou X, Hansson GK: Immunotherapy With Tolerogenic Apolipoprotein B-100Loaded Dendritic Cells Attenuates Atherosclerosis in Hypercholesterolemic Mice. Circulation 2011, 123:1083-1091.

28. Calara F, Silvestre M, Casanada F, Yuan N, Napoli C, Palinski W: Spontaneous plaque rupture and secondary thrombosis in apolipoprotein E-deficient and LDL receptor-deficient mice. J Pathol 2001, 195:257-263.

29. Nakashima Y, Plump AS, Raines EW, Breslow JL, Ross R: ApoE-deficient mice develop lesions of all phases of atherosclerosis throughout the arterial tree. Arterioscler Thromb 1994, 14:133-140.

30. Chase A, Jackson CL, Angelini GL, Suleiman MS: Coronary artery disease progression is associated with increased resistance of hearts and myocytes to cardiac insults. Crit Care Med 2007, 35:2344-2351.
31. Coleman R, Hayek T, Keidar S, Aviram M: A mouse model for human atherosclerosis: Long-term histopathological study of lesion development in the aortic arch of apolipoprotein E-deficient (E0) mice. Acta Histochem 2006, 108:415-424.

32. Dworschak M, d'Uscio LV, Breukelmann D, Hannon JD: Increased tolerance to hypoxic metabolic inhibition and reoxygenation of cardiomyocytes from apolipoprotein E-deficient mice. Am J Physiol Heart Circ Physiol 2005, 289:H160-167.

33. Kuhlencordt PJ, Gyurko R, Han F, Scherrer-Crosbie M, Aretz TH, Hajjar R, Picard MH, Huang PL: Accelerated Atherosclerosis, Aortic Aneurysm Formation, and Ischemic Heart Disease in Apolipoprotein E/Endothelial Nitric Oxide Synthase Double-Knockout Mice. Circulation 2001, 104:448-454.

34. Saraste A, Kytö V, Laitinen I, Saraste M, Leppänen P, Ylä-Herttuala S, Saukko P, Hartiala J, Knuuti J: Severe coronary artery stenoses and reduced coronary flow velocity reserve in atherosclerotic mouse model: Doppler echocardiography validation study. Atherosclerosis 2008, 200:89-94

35. Caligiuri G, Levy B, Pernow J, Thoren P, Hansson GK: Myocardial infarction mediated by endothelin receptor signaling in hypercholesterolemic mice. Proc Natl Acad Sci USA 1999, 96:6920-6924

36. Li G, Tokuno S, Tähepôld P, Vaage J, Löwbeer C, Valen G: Preconditioning protects the severely atherosclerotic mouse heart. Ann Thorac Surg 2001, 71:1296-1303.

37. Braun A, Trigatti BL, Post MJ, Sato K, Simons M, Edelberg JM, Rosenberg RD, Schrenzel M, Krieger M: Loss of SR-BI Expression Leads to the Early Onset of Occlusive Atherosclerotic Coronary Artery Disease, Spontaneous Myocardial Infarctions, Severe Cardiac Dysfunction, and Premature Death in Apolipoprotein E-Deficient Mice. Circ Res 2002, 90:270-276.

38. Glagov S, Weisenberg E, Zarins CK, Stankunavicius R, Kolettis GJ: Compensatory Enlargement of Human Atherosclerotic Coronary Arteries. N Engl J Med 1987, 316:1371-1375.

39. Bentzon JF, Pasterkamp G, Falk E: Expansive Remodeling Is a Response of the Plaque-Related Vessel Wall in Aortic Roots of ApoE-Deficient Mice: An Experiment of Nature. Arterioscler Thromb Vasc Biol 2003, 23:257-262.

40. Lutgens $E$, de Muinck ED, Heeneman S, Daemen MJAP: Compensatory Enlargement and Stenosis Develop in ApoE-/- and ApoE*3-Leiden Transgenic Mice. Arterioscler Thromb Vasc Biol 2001, 21:1359-1365.

41. Fuessl RT, Kranenberg E, Kiausch U, Baer FM, Sechtem U, Hopp HW: Vascular remodeling in atherosclerotic coronary arteries is affected by plaque composition. Coron Artery Dis 2001, 12:91-97.

42. Pasterkamp G, Schoneveld AH, van der Wal AC, Haudenschild CC, Clarijs RJG, Becker AE, Hillen B, Borst C: Relation of arterial geometry to luminal narrowing and histologic markers for plaque vulnerability: the remodeling paradox. J Am Coll Cardiol 1998, 32:655-662.

43. Reddy HK, Koshy SKG, Foerst J, Sturek M: Remodeling of Coronary Arteries in Diabetic Patients?An Intravascular Ultrasound Study. Echocardiography 2004, 21:139-144.

44. Nicholls SJ, Tuzcu EM, Kalidindi S, Wolski K, Moon K, Sipahi I, Schoenhagen P, Nissen SE: Effect of Diabetes on Progression of Coronary Atherosclerosis and Arterial Remodeling: A Pooled Analysis of 5 Intravascular Ultrasound Trials. J Am Coll Cardiol 2008, 52:255-262.

45. Lakatta EG: Arterial and Cardiac Aging: Major Shareholders in Cardiovascular Disease Enterprises: Part III: Cellular and Molecular Clues to Heart and Arterial Aging. Circulation 2003, 107:490-497.

46. Perrone-Filardi P, Pace L, Prastaro M, Piscione F, Betocchi S, Squame F, Vezzuto P, Soricelli A, Indolfi C, Salvatore M, Chiariello M: Dobutamine Echocardiography Predicts Improvement of Hypoperfused Dysfunctional Myocardium After Revascularization in Patients With Coronary Artery Disease. Circulation 1995, 91:2556-2565.

47. Vincelette J, Martin-Mcnulty B, Vergona R, Sullivan ME, Wang Y: Reduced cardiac functional reserve in apolipoprotein $E$ knockout mice. Trans/ Res 2006, 148:30-36.

48. Daniels A, Van Bilsen M, Janssen BJA, Brouns AE, Cleutjens JPM, Roemen THM, Schaart G, Van Der Velden J, Van Der Vusse GJ, Van Nieuwenhoven FA: Impaired cardiac functional reserve in type 2 diabetic $\mathrm{db} / \mathrm{db}$ mice is associated with metabolic, but not structural, remodelling. Acta Physiol 2010, 200:11-22.

49. Heusch G, Schulz R, Rahimtoola SH: Myocardial hibernation: a delicate balance. Am J Physiol Heart Circ Physio 2005, 288:H984-H999. 
50. Frangogiannis NG: The pathological basis of myocardial hibernation. Histol Histopathol 2003, 18:647-655.

51. Dewald O, Frangogiannis NG, Zoerlein M, Duerr GD, Klemm C,

Knuefermann P, Taffet G, Michael LH, Crapo JD, Welz A, Entman ML:

Development of murine ischemic cardiomyopathy is associated with a

transient inflammatory reaction and depends on reactive oxygen species. Proc Natl Acad Sci USA 2003, 100:2700-2705.

52. May D, Gilon D, Djonov V, Itin A, Lazarus A, Gordon O, Rosenberger C, Keshet E: Transgenic system for conditional induction and rescue of chronic myocardial hibernation provides insights into genomic programs of hibernation. Proc Natl Acad Sci USA 2008, 105:282-287.

doi:10.1186/1475-2840-10-59

Cite this article as: Heinonen et al:: Left ventricular dysfunction with reduced functional cardiac reserve in diabetic and non-diabetic LDLreceptor deficient apolipoprotein B100-only mice. Cardiovascular Diabetology 2011 10:59.

\section{Submit your next manuscript to BioMed Central} and take full advantage of:

- Convenient online submission

- Thorough peer review

- No space constraints or color figure charges

- Immediate publication on acceptance

- Inclusion in PubMed, CAS, Scopus and Google Scholar

- Research which is freely available for redistribution

Submit your manuscript at www.biomedcentral.com/submit 